\section{Trends in tuberculosis in the UK}

\author{
Philippe Glaziou, ${ }^{1}$ Katherine Floyd, ${ }^{1}$ Mario Raviglione ${ }^{2}$
}

The industrial revolution, starting in the 18th-century England and coupled with poverty, urbanisation and squalor, created an optimal environment for the propagation of $\mathrm{TB}^{1}$ One in four deaths were due to TB by the early 19 th century. ${ }^{2}$ Since then, the remarkable decline in the burden of TB at an average annual rate of $3.3 \%$ between 1913 and 1940, documented in one of the longest ever recorded time series of data on the burden of TB (figure 1), a notifiable disease in the UK since 1912, was only interrupted by the two world wars. During those years, the temporary peaks in both incidence and mortality were linked to impoverishment of the population and poorer nutrition. In the years following the Second World War, as in other Western European countries, the fall in TB burden significantly accelerated to an average annual decline of $10 \%$ between 1955 and 1960 following the advent of modern chemotherapy. This allowed a reduction in transmission and drastically improved the prognosis of the disease, with a case fatality ratio (approximated as the ratio of mortality over incidence) of about $50 \%$ in the prechemotherapy era dropping to less than $10 \%$ within a decade of the introduction of chemotherapy. A decline in the effective contact rate ${ }^{3}$ and low TB rates have also been achieved in other settings that have in common a combination of near-universal access to high-quality $\mathrm{TB}$ diagnosis and treatment, social protection and general socioeconomic development with improved nutrition and living and working conditions. ${ }^{45}$

In the light of the mid-20th-century successes, it soon became a common belief that TB had been conquered and was a disease of the past. However, some 30 years later in the early 1990 s, a resurgence of TB was recorded in many parts of the industrialised world, ${ }^{67}$ attributed to a variety of factors including the dismantling of TB control programmes, ${ }^{8}$ increased migration, ${ }^{9} 10$ the spread of $\mathrm{HIV}^{11}$ an increase in drug-resistant $\mathrm{TB}^{12}$ increases of some non-communicable diseases that are risk factors

${ }^{1}$ Global TB Programme, World Health Organization, Geneva, Switzerland

${ }^{2}$ Global Health Centre, University of Milan, Milan, Italy

Correspondence to Dr Philippe Glaziou, Global TB Programme, World Health Organization, Geneva 1211, Switzerland; glazioup@who.int for TB, including type 2 diabetes associated with the global pandemic of obesity, ${ }^{13}$ as well as economic crises and growing inequality in wealth and access to health. ${ }^{411}$ As in most high-income countries, the epidemiology of $\mathrm{TB}$ in the UK progressively changed from one of sustained transmission in the general population to one dominated by reactivation of an infection acquired either long in the past or more recently in another country with a high level of TB transmission. There is currently very limited ongoing transmission in the UK, and three out of four cases detected arise in people infected abroad. ${ }^{14}$ While TB may sometimes be transmitted within migrant communities, transmission from migrant groups into host country populations is normally limited or undocumented. ${ }^{9}$

After three consecutive decades of a relentless increase of the rate of incidence at an average of $1.9 \% /$ year between 1980 and 2012, TB resumed its secular decline in England in the past 5 years. However, the future trajectory of TB incidence is uncertain and maintenance of the current favourable trends will require strict adherence to the measures undertaken lately. Indeed, to achieve these results and eliminate $\mathrm{TB}$ as a public health problem in England, $10 \mathrm{key}$ areas for action were prioritised in the Collaborative TB Strategy for England $2015-2020,{ }^{15}$ in line with the WHO framework towards TB elimination that was developed for low-incidence countries. ${ }^{10}$ The key areas included reducing TB among new migrants through testing for latent TB infection and its treatment; reducing diagnostic delay through awareness raising and improving accessibility of services; maintaining the quality of TB treatment and care services to ensure continued high treatment completion; and addressing the social factors associated with $\mathrm{TB}$, including the specific needs of underserved populations.

In Thorax, Thomas et al ${ }^{16}$ present an elegant epidemiological analysis of the reasons for the recent reversal of $\mathrm{TB}$ notifications, likely reflecting a real incidence decrease. They argue that a combination of four factors-the pre-entry screening programme targeting immigrants, a reduction in the number of new immigrants from high TB burden countries, improvements in TB control leading to a reduction in $\mathrm{TB}$ transmission and the early impact of testing and treating patients with diagnosed latent TB infection-explains this decline.

As a result of these factors, TB rates are decreasing in virtually all subpopulations and getting closer to elimination levels in the non-foreign-born population in the UK. This phenomenon is similar to that observed in other high-income countries. ${ }^{17}$ In the globalised world of today with much lower barriers between countries and with easier and rapid travel opportunities, TB can be acquired anywhere and swiftly 'exported' worldwide. The prospect of further progress towards

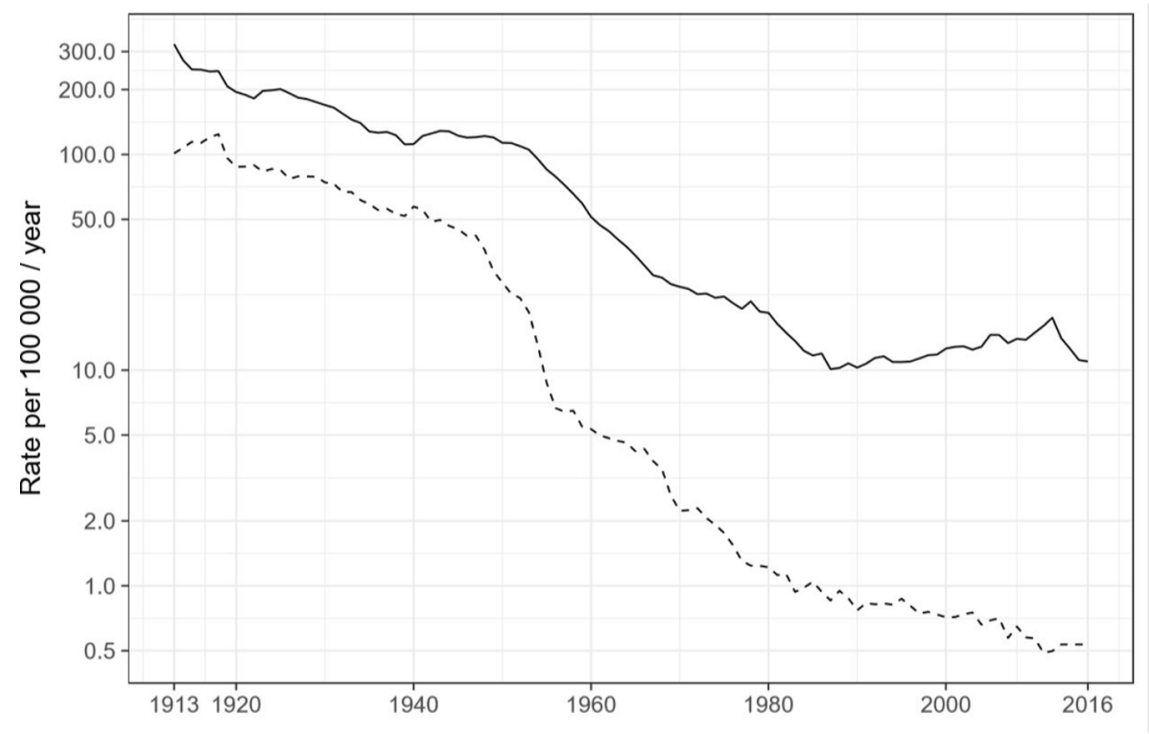

Figure 1 TB incidence (solid line) and mortality (dashed line) rates per 100000 populations per year in England and Wales, ${ }^{20}$ 1913-2016. 
elimination in low-incidence countries hinges therefore on the effectiveness of measures taken to treat, control and prevent TB anywhere in the world. ${ }^{18}$ Commitments made in the Declaration from the WHO Global Ministerial Conference on Ending $\mathrm{TB}$ in the Sustainable Development Era that was held in Moscow, Russian Federation, in November 2017 and the upcoming UN General Assembly High-Level Meeting on TB in September $2018^{19}$ provide greater hope that the multisectoral efforts required to put all countries on the path to ending the TB epidemic can be concretely pursued and galvanised. Complacency is in fact one of the greatest risks public health officials and all those engaged in anti-TB activities must face. The lower burden of TB in the UK may lead to lower visibility, a phenomenon already observed almost everywhere in the last decades of the 20 th century when the success of treatment programmes made most believe that the multicentury struggle against TB had ended. This may translate into weaker political will, reduction of public interest, insufficient public health responses and clinical capacity domestically. It may also lead to inadequate domestic, bilateral and multilateral commitments to funding $\mathrm{TB}$ prevention and control efforts where they are needed the most, whether it is the high-incidence, poorest parts of London, or low-income countries where the epidemic is not yet under control.

Contributors All three authors contributed to writing this editorial.

Funding The authors have not declared a specific grant for this research from any funding agency in the public, commercial or not-for-profit sectors.

Competing interests None declared.
Patient consent Not required.

Provenance and peer review Commissioned; externally peer reviewed.

Data sharing statement There are no unpublished data used in this editorial.

Author note Mario Raviglione was the former GTB Director.

\section{(1) OPEN ACCESS}

Open access This is an open access article distributed in accordance with the Creative Commons Attribution Non Commercial (CC BY-NC 4.0) license, which permits others to distribute, remix, adapt, build upon this work non-commercially, and license their derivative works on different terms, provided the original work is properly cited and the use is non-commercial. See: http:// creativecommons.org/licenses/by-nc/4.0/

(c) Article author(s) (or their employer(s) unless otherwise stated in the text of the article) 2018. All rights reserved. No commercial use is permitted unless otherwise expressly granted.

A) Check for updates

To cite Glaziou P, Floyd K, Raviglione M. Thorax 2018;73:702-703.

Accepted 3 April 2018

Published Online First 19 April 2018

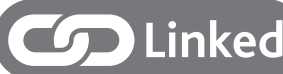

http://dx.doi.org/10.1136/thoraxjnl-2017-211074

Thorax 2018;73:702-703.

doi:10.1136/thoraxjnl-2018-211537

\section{REFERENCES}

1 Dubos RJ, Dubos J. The white plague: tuberculosis, man, and society: Rutgers University Press, 1952.

2 Landers J. Death and the metropolis: studies in the demographic history of London, 1670-1830: Cambridge University Press, 2006

3 Vynnycky E, Fine PE. Interpreting the decline in tuberculosis: the role of secular trends in effective contact. Int J Epidemiol 1999;28:327-34.
4 Lönnroth K, Jaramillo E, Williams BG, et al. Drivers of tuberculosis epidemics: the role of risk factors and social determinants. Soc Sci Med 2009;68:2240-6.

5 Ploubidis GB, Palmer MJ, Blackmore C, et al. Social determinants of tuberculosis in Europe: a prospective ecological study. Eur Respir 」 2012:40:925-30.

6 Torjesen I. Tuberculosis cases in England will outnumber US in two years unless trends are reversed. BMJ 2015;350:h355.

7 Davies PD, Williams CS. Tuberculosis is increasing in England and Wales. Tuber Lung Dis 1993;74:350-1.

8 Zumla A. The white plague returns to London--with a vengeance. Lancet 2011;377:10-11.

9 Dahle UR, Eldholm V, Winje BA, et al. Impact of immigration on the molecular epidemiology of Mycobacterium tuberculosis in a low-incidence country. Am J Respir Crit Care Med 2007;176:930-5.

10 Lönnroth K, Migliori GB, Abubakar I, et al. Towards tuberculosis elimination: an action framework for low-incidence countries. Eur Respir J 2015;45:ERJ-021402014-52.

11 Zumla A, Atun R, Maeurer M, et al. Eliminating tuberculosis and tuberculosis-HIV co-disease in the 21st century: key perspectives, controversies, unresolved issues, and needs. I Infect Dis 2012:205(Suppl 2):S141-S146

12 Nathanson E, Nunn P, Uplekar M, et al. MDR tuberculosis--critical steps for prevention and control. N Engl J Med 2010;363:1050-8.

13 Creswell J, Raviglione M, Ottmani S, et al. Tuberculosis and noncommunicable diseases: neglected links and missed opportunities. Eur Respir J 2011;37:1269-82.

14 Public Health England. Tuberculosis in England 2016 report: Public Health England, 2018. https://www. tbalert.org/wp-content/uploads/2016/09/PHE_TB Annual_Report_2016.pdf.

15 Abubakar I, Thomas HL, Morgan M, et al. A collaborative strategy to tackle tuberculosis in England. Lancet 2015:385:312-3.

16 Thomas RH, Harris R, Muzyamba M, et al. Explaining the one third reduction in tuberculosis incidence in the UK, 2011-2015: a retrospective population-based study. Thorax 2018.

17 Voniatis C, Migliori GB, Voniatis M, et al. Tuberculosis elimination: dream or reality? The case of Cyprus. Eur Respir I 2014:44:543-6.

18 Schwartzman K, Oxlade O, Barr RG, et al. Domestic returns from investment in the control of tuberculosis in other countries. N Engl J Med 2005;353:1008-20.

19 Raviglione M, Uplekar M, Weil D, et al. Tuberculosis makes it onto the international political agenda for health...finally. Lancet Glob Health 2018;6:e20-e21.

20 GOV.UK. Tuberculosis (TB): annual notification and mortality data (1913 onwards). https://www.gov. uk/government/publications/tuberculosis-tb-annualnotifications-1913-onwards (accessed 5 Feb 2018). 